\title{
The prevalence of ocular surface complaints in Brazilian patients with glaucoma or ocular hypertension
}

\author{
Prevalência de sintomas da doença da superfície ocular em pacientes brasileiros com glaucoma ou \\ hipertensão ocular
}

Vital Paulino Costa ${ }^{1}$, Italo Mundialino Marcon², Roberto Pedrosa Galvão Filho ${ }^{3}$, Roberto Freire Santiago Malta ${ }^{4}$

\begin{abstract}
Purpose: To examine the prevalence of ocular surface complaints in Brazilian patients with glaucoma or ocular hypertension who used topical intraocular pressure (IOP)-lowering regimens.

Methods: In this multicenter, noninterventional, single-visit study, adults with glaucoma or ocular hypertension treated with an IOP-lowering regimen were administered the 12-item ocular surface disease index (OSDI) questionnaire. Each response was scored on a 5-point scale, with 0 indicating symptom present none of the time and 4 indicating symptom present all of the time. The average of the 12 item responses for each patient was transformed to a scale from 0 to 100 , with higher scores representing worse disabilities. OSDI results then were categorized as absence of OSD (scores of 0-12), mild OSD (scores of 13-22), moderate OSD (scores of 23-32), or severe OSD (scores of 33100).

Results: The 173 enrolled patients had a mean age of 61.2 years, were women in $65.3 \%$ of cases, and had glaucoma in $89.0 \%$ of cases and ocular hypertension in $11.0 \%$ of cases. OSDI scores for 158 patients using 1 IOP-lowering therapy indicated no OSD in $37.3 \%$ of patients (59/158), mild OSD in $20.9 \%$ (33/158), moderate OSD in $17.1 \%(27 / 158)$, and severe OSD in 24.7\% (39/158). For the 120 patients using 1 IOP-lowering medication and having a known duration of diagnosis of glaucoma or ocular hypertension, mean OSDI scores were numerically higher (worse) for the 39 patients with a diagnosis $\geq 6$ years long (score 25 [ \pm 20$]$, indicating moderate OSD) than for the 81 patients with a diagnosis lasting $<6$ years (score 22 [ \pm 20], indicating mild OSD); however, no significant differences in OSDI scores by duration of diagnosis were evident in means $(P=0.49)$, distributions $(P \geq 0.26)$, or correlation $(P=0.77)$.
\end{abstract}

Conclusions: A large proportion of Brazilian patients treated with 1 IOP-lowering therapy had some ocular surface complaints.

Keywords: Glaucoma; Ocular hypertension/therapy; Dry eye syndromes/drug therapy; Preservatives, pharmaceutical/therapeutic use; Brazil

\section{RESUMO}

Objetivo: Avaliara prevalência de sintomas decorrentes de doença desuperfície ocular (DSO) em pacientes brasileiros com glaucoma ou hipertensão ocular que utilizam tratamento ocular tópico para redução da pressão intraocular (PIO).

Método: Nesteestudo multicêntrico, não intervencional de uma única visita, pacientes adultos com glaucoma ou hipertensão ocular em tratamento para redução da pressão intraocular (PIO) responderam aos 12 itens do questionário "índice de doença da superfície ocular" (OSDI). Cada resposta foi pontuada numa escala de 5 pontos, com 0 (zero) indicando a ausência de sintomas e 4 indicando sintomas presentes todo o tempo. A média de respostas dos 12 itens para cada paciente foi transformada numa escala de 0 a 100, com pontuações mais elevadas representando piores deficiências. Os resultados do OSDI foram categorizados como ausência de DSO (pontuação de 0-12), DSO leve (pontuação de 13-22), DSO moderada (pontuação de 23-32) ou DSO grave (pontuação de 33-100).

Resultados: Os 173 pacientes incluídos apresentavam idade média de 61,2 anos, $65,3 \%$ eram mulheres (65,3\%), tinham glaucoma em $89,0 \%$ dos casos e hipertensão ocular em 11,0\% dos casos. As pontuações do OSDI para os 158 pacientes utilizando uma medicação para redução da PIO indicaram "DSO ausente" em 37,3\% dos pacientes (59/158), "DSO leve" em 20,9\% (33/158), "DSO moderada" em 17,1\% (27/158) e "DSO grave" em 24.7\% (39/158). Para os 120 pacientes utilizando medicação redutora da PIO e com duração conhecida do diagnóstico de glaucoma ou hipertensão ocular, a pontuação média do OSDI foi numericamente superior (pior) para 39 pacientes com diagnóstico realizado há mais de 6 anos (pontuação 25 [ \pm 20$]$ indicando DSO moderado) do que para 81 pacientes com o diagnóstico realizado há menos de 6 anos (pontuação 22 [ \pm 20$]$ indicando DSO leve); no entanto, não houve diferença estatisticamentesignificativa na média da pontuação OSDI na duração do diagnóstico $(P=0.49)$, distribuição $(P \geq 0,26)$, ou correlação $(P=0,77)$.

Conclusão: Uma grande proporção de pacientes brasileiros tratados com uma medicação para redução da PIO apresenta sintomas decorrentes de doença da superfície ocular (DSO).

Descritores: Glaucoma; Hipertensão ocular/quimioterapia; Síndrome do olho seco/ quimioterapia; Conservantes farmacêuticos/uso terapêutico
Submitted for publication: November 9, 2012

Accepted for publication: March 12, 2013

Study carried out Hospital das Clínicas da Faculdade de Medicina, Universidade de São Paulo - São Paulo (SP), Brazil.

1 Physician, Glaucoma Service, Universidade Estadual de Campinas - Campinas (SP), Brazil.

2 Physician, Glaucoma Service, Santa Casa de Porto Alegre - Porto Alegre (RS), Brazil.

${ }^{3}$ Physician, Research Center, Instituto de Olhos do Recife - Recife (PE), Brazil.

${ }^{4}$ Physician, Hospital das Clínicas da Faculdade de Medicina, Universidade de São Paulo - São Paulo (SP), Brazil.
Funding: Alcon Research, Ltd. sponsored this study and provided the services of medical writers and editors for assistance with preparing this manuscript.

Disclosure of potential conflicts of interest: V.P.Costa, has received a grant from Alcon and he is a consultant and a board member for Alcon and Merck, has received a grant and provision of writing assistance, medicines, equipment, or administrative support from the Instituto de Olhos do Recife; I.M.Marcon, None; R.P.Galvão Filho, has received a grant and provision of writing assistance, medicines, equipment, or administrative support from the Instituto de Olhos do Recife; R.F.S.Malta, has received a grant from Faculdade de Medicina da Universidade de São Paulo.

Corresponding author: Vital Paulino Costa. Universidade Estadual de Campinas - UNICAMP. Rua Mato Grosso, 306 - São Paulo (SP) - 01239-040 - Brazil - E-mail: vp.costa@uol.com.br

The study protocol and the participating investigators were approved as number 22/01/2011 by the Comitê de Ética em Pesquisa do Hospital Samaritano affiliated with the Comitê Nacional de Ética em Pesquisa (CONEP). Because this was a noninterventional study, it was not registered on a public clinical trials registry. 


\section{INTRODUCTION}

Ocular surface disease (OSD) is a multifactorial ocular condition associated with inadequate tear film volume, tear film instability, and damage to the ocular surface ${ }^{(1)}$. Clinically meaningful signs such as rapid tear film breakup, high tear osmolarity, and increased ocular surface staining also may be observed in patients with OSD ${ }^{(2)}$. Individuals with OSD may experience the symptoms of ocular dryness, burning/stinging, itching, irritation, tearing, foreign body sensation, redness, and blurred vision, at varying levels of severity ${ }^{(2)}$. Because of the overlap of the signs and symptoms of OSD versus dry eye disease, the literature to date has often treated these diseases interchangeably. Studies suggest that OSD or dry eye disease can negatively affect overall quality of life ${ }^{(3)}$, functional visual acuity ${ }^{(4)}$, and the ability to carry out daily tasks (eg, driving and participating in sports and other leisure activities, such as reading and cooking) ${ }^{(4)}$.

Approximately $15 \%$ of the general elderly population in the United States experiences some level of symptomatic OSD ${ }^{(5)}$. Studies in the United States ${ }^{(6)}$, Australia(7), and Brazil(8) have indicated that the prevalence of OSD or dry eye is higher in glaucoma patients than in the nonglaucomatous population. The etiology of OSD in patients with glaucoma is thought to be multifactorial. Anterior segment ocular disorders such as allergy, blepharitis, dry eye, or eyelid anatomical abnormalities may contribute to the onset or exacerbation of OSD ${ }^{(2)}$. The use of preservative-containing topical ocular medications to lower intraocular pressure (IOP) may be another key factor. Topical ocular IOP-lowering drugs that contain the preservative benzalkonium chloride (BAK) may trigger or exacerbate OSD by inducing ocular surface damage ${ }^{(9)}$. The effects of BAK on the ocular surface may increase over time due to chronic exposure, since IOP-lowering medications are generally administered daily for many years, and since multiple medications are sometimes required to achieve and maintain desired IOP-lowering effects ${ }^{(9)}$.

A recent global study noted that patients who were enrolled at clinics in Latin America (Argentina, Colombia, and Mexico), had OSD that was significantly worse than the OSD of Asian patients or Caucasian patients globally ${ }^{(10)}$. Since race and geography may be important to OSD prevalence, this study was designed to determine the prevalence of ocular surface complaints in a Brazilian population of patients with glaucoma or ocular hypertension who were on an IOP-lowering regimen.

\section{METHODS}

This multicenter, noninterventional, single-visit study at four study centers in Brazil evaluated the ocular surface complaints of patients with glaucoma or ocular hypertension. Upon entry, all patients provided their written informed consent. An independent Ethics Committee approved the protocol and the qualifications of all of the participating investigators. The study was conducted in accordance with Good Clinical Practices and the ethical principles described within the Declaration of Helsinki.

During a regularly scheduled clinic visit, eligible patients completed the Ocular Surface Disease Index (OSDI) questionnaire. Demographic information, medical histories, and use of concomitant medications, including artificial tears, were recorded. Eligible patients were men and women of any race or ethnicity, at least 18 years of age, who had a best-corrected visual acuity of at least 20/60 Snellen in each eye, who were diagnosed with ocular hypertension or glaucoma (closed-angle, open-angle, pseudoexfoliation, or pigment dispersion), and who were receiving any topical ocular regimen to lower IOP.

The OSDI is a 12 item, disease specific quality-of-life questionnaire used to quantify the effect of dry eye on vision-related quality of life. The OSDI questionnaire has been validated for its test-retest reliability and its usefulness to clinically differentiate among absence of OSD, mild to moderate OSD, and severe OSD ${ }^{(11)}$. The questionnaire includes three subscales: ocular discomfort (OSDI symptoms), func- tioning (OSDI-function), and environmental triggers (OSDI-triggers). The individual items within the subscales refer to a 1-week recall period; possible responses to each item are based on the frequency of the associated disturbance. Each response was scored based on a scale that ranged from 0 (none of the time) to 4 (all of the time). The average score for each of the 12 items rated by each patient was transformed to a scale ranging from 0 to 100, with higher scores representing worse disability. Ocular surface disease index results then were categorized as absence of OSD (scores of 0-12), mild OSD (scores of 13-22), moderate OSD (scores of 23-32), or severe OSD (scores of 33100), as previously described ${ }^{(11,12)}$.

Descriptive statistics (including number, percentage, mean, standard deviation, and range) were calculated for demographics, baseline characteristics, and OSDI scores. Mean OSDI scores also were summarized by the categorical time since diagnosis of glaucoma or ocular hypertension (ie, 1 category for patients with a diagnosis shorter than the mean number of years since diagnosis and 1 category for patients with a diagnosis longer than or equal to the mean number of years since diagnosis); the comparison of the mean values of those 2 subgroups was performed using a 2-sample $t$-test, with inferences drawn at an alpha level of 0.05. Comparisons between groups of the distribution of patients with normal OSDI scores vs. all other patients and of the distribution of patients with severe OSD scores vs. all other patients were performed using a Chi-square test. The interaction between OSDI scores and duration of current glaucoma therapy was analyzed using a Pearson correlation. Statistics were analyzed using Statistica version 5.1/97.

\section{RESULTS}

A total of 173 patients were enrolled at 4 investigational centers in Brazil (Table 1). The 173 patients were 13 to 88 years of age, with a mean ( \pm standard deviation, SD) age of $61.2( \pm 14.3)$ years. The majority of patients (68.8\%) were Caucasian and $65.3 \%$ were women. Most patients (89.0\%) had a diagnosis of glaucoma (primary openangle glaucoma, 74.0\%; closed-angle glaucoma, 13.3\%; open-angle glaucoma with pseudoexfoliation, 1.7\%) and the remainder (11.0\%) had ocular hypertension. Fourteen patients were excluded from the analysis for protocol deviations (8 patients who were using an "unknown" number of IOP-lowering medications, and 6 patients who were using more than 1 medication), leaving 159 patients eligible for analysis.

One patient did not answer all of the OSDI questions, yielding evaluable OSDI data for 158 patients. Of those, 37.3\% (59 of 158) had OSDI scores indicating absence of OSD. The remainder of the population - approximately two thirds of the patients $(62.7 \%, 99$ of 158; $95 \%$ confidence interval $55.2 \%$ to $70.2 \%$ ) - had OSDI scores indicating some degree of OSD. Scores indicated mild OSD in 33 of 158 patients (20.9\%), moderate OSD in 27 of 158 patients (17.1\%), and severe OSD in 39 of 172 patients (24.7\%); (Figure 1).

In the overall population of 173 patients, 40 had an unknown duration of diagnosis of glaucoma or ocular hypertension. Of those with a known duration $(n=133)$, the mean $( \pm S D)$ time since diagnosis of glaucoma or ocular hypertension was $6.0( \pm 6.9)$ years. That mean value was used as the basis for dividing patients into categories of duration since glaucoma diagnosis (ie, $<6$ years and $\geq 6$ years). After excluding for protocol deviations related to number of IOP-lowering medications and for incomplete responses to the OSDI questionnaire, 120 patients were evaluable for duration of diagnosis versus OSDI score. Mean OSDI scores were higher (worse) for patients in the longer-duration diagnosis category than for those in the shorter-duration diagnosis category. Specifically, evaluable patients who had a diagnosis of $<6$ years $(n=81)$ had a mean $( \pm$ SD) OSDI score of 22 $( \pm 20)$ units, indicating mild severity OSD, while patients with a diagnosis of 6 years or longer $(n=39)$ had a mean $( \pm$ SD) OSDI score of 25 ( \pm 20 ) units, indicating moderate severity OSD. However, diffe- 
Table 1. Demographic and baseline characteristics

\begin{tabular}{|c|c|}
\hline Characteristics & $\begin{array}{c}\text { Total } \\
(\mathrm{N}=173)\end{array}$ \\
\hline \multicolumn{2}{|l|}{ Age, years } \\
\hline Mean (standard deviation) & $61.2(14.3)$ \\
\hline Range (minimum, maximum) & $(13,88)^{a}$ \\
\hline \multicolumn{2}{|l|}{ Sex, n (\%) } \\
\hline Men & $60(34.7)$ \\
\hline Women & $113(65.3)$ \\
\hline \multicolumn{2}{|l|}{ Race, n (\%) } \\
\hline Caucasian & $119(68.8)$ \\
\hline Black & $28(16.2)$ \\
\hline Asian & $3(1.7)$ \\
\hline Other & $23(13.3)$ \\
\hline \multicolumn{2}{|l|}{ Diagnosis type, $\mathrm{n}(\%)$} \\
\hline Ocular hypertension & $19(11.0)$ \\
\hline Primary open-angle glaucoma & $128(74.0)$ \\
\hline Open-angle glaucoma with pseudoexfoliation & $3(1.7)$ \\
\hline Open-angle glaucoma with pigment dispersion & $0(0.0)$ \\
\hline Closed-angle glaucoma & $23(13.3)$ \\
\hline \multicolumn{2}{|l|}{ Time since diagnosis, years } \\
\hline Mean (standard deviation) & $6(6.9)$ \\
\hline$<6$ years, $\mathrm{n}(\%)$ & $86(49.7)$ \\
\hline$\geq 6$ years, $\mathrm{n}(\%)$ & $47(27.2)$ \\
\hline Unknown duration, n (\%) & $40(23.1)$ \\
\hline \multicolumn{2}{|l|}{ Number of glaucoma medications } \\
\hline Mean (standard deviation) & $1.0(0.2)$ \\
\hline $1, n(\%)^{b}$ & $159(91.9)$ \\
\hline 2 or $3, \mathrm{n}(\%)$ & $6(3.5)$ \\
\hline Unknown, n (\%) & $8(4.6)$ \\
\hline
\end{tabular}

a $=$ one patient younger than 18 years of age was enrolled and included in the study endpoint analyses. ${ }^{b}=$ Included monotherapies and fixed-combination therapies.

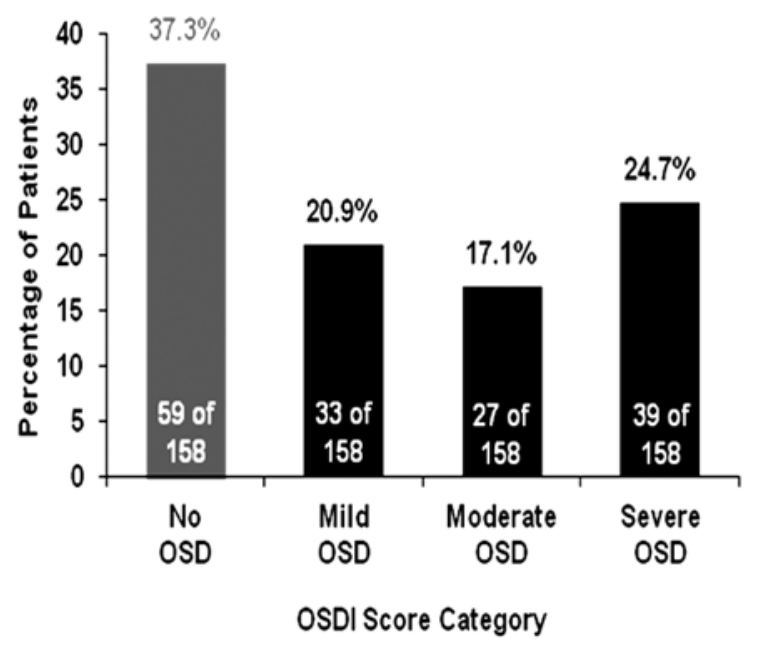

OSD = ocular surface disease.

Figure 1. Ocular surface disease index (OSDI) score category results for patients with glaucoma or ocular hypertension at four study centers in Brazil. rences in OSDI scores in terms of duration of diagnosis were not statistically significant by $t$-test of means $(P=0.49)$ or when investigated by Pearson correlation $(P=0.77)$. The poorer mean OSDI score in the longer-duration group (with respect to the shorter-duration group) appeared to be due to a smaller proportion of patients without OSD and a larger proportion of patients with severe OSD, as shown in figure 2A. These proportions were not significantly different by Chisquare tests between shorter-duration and longer-duration groups ( $P=0.43$ for severe OSD and $P=0.26$ for absence of OSD) as shown in figure $2 \mathrm{~B}$.

\section{DISCUSSION}

In individuals with glaucoma or ocular hypertension, ocular surface complaints are common. Scores on OSDI questionnaires in this study indicated that $62.7 \%$ of patients who had glaucoma or ocular hypertension and who were using 1 IOP-lowering medication had mild, moderate, or severe OSD. That overall prevalence of OSD was slightly higher than the reported prevalence of dry eye among glaucoma patients in Germany (53\%)(13) or the OSDI-based prevalence of OSD among glaucoma patients in the United States (48\%-59\%) $)^{(1,14)}$ or globally $(59.2 \%)^{(10)}$. When compared to other OSDI-based studies, the prevalence of severe OSD in patients with glaucoma or ocular hypertension observed in this study (24.7\%) was slightly higher than its prevalence in one previous study in the United States $(13.8 \%)^{(14)}$, was approximately similar to its prevalence in a global study $(20.3 \%)^{(10)}$, and was slightly lower than its prevalence $(27 \%)$ reported in another study in the United States ${ }^{(1)}$. However, results from the current study of patients using 1 IOP-lowering medication cannot easily be compared with other studies of patients using 1 or more IOP-lowering medications, since many of those studies have reported that relationships may exist between higher numbers of IOP-lowering medications and worse signs or symptoms of OSD or dry eye disease ${ }^{(1,11,13,14)}$.

The high prevalence of mild, moderate, or severe OSD as classified in this study may be multifactorial, with factors including anterior segment ocular disorders such as allergy, blepharitis, dry eye, or eyelid anatomical abnormalities ${ }^{(2)}$. Moreover, environmental issues in Brazil may influence ocular surface integrity ${ }^{(15)}$. In addition, results may be partially attributed to frequent use of BAK-preserved medications ${ }^{(9)}$. Due to its broad spectrum of antimicrobial efficacy and its effects on the tight junctions between corneal epithelial cells (which facilitates ocular penetration of active compounds), BAK is the most widely used preservative in ophthalmic preparations ${ }^{(9,16)}$. When compared with preservative-free medication, long-term topical ocular use of BAK-preserved medications in patients with glaucoma has been associated with ocular surface alterations. One such alteration is a decrease in goblet cell density associated with BAK-preserved therapy that was significantly larger than the decrease with unpreserved therapy ${ }^{(17)}$. Another such alteration is lower tear production volume and greater tear film instability in patients using BAK-preserved therapies versus those using unpreserved therapy ${ }^{(18)}$. These BAK-induced effects may be reversible or partially reversible in some cases; switching patients with mild OSD from a BAK-preserved IOP-lowering therapy to an alternatively preserved IOP-lowering therapy resulted in a mean OSDI score that indicated absence of clinically significant OSD and that was significantly better than the mean OSDI score for patients who continued on a BAK-preserved IOP-lowering therapy ${ }^{(19)}$.

Alternatives to BAK-preserved therapies include preservative-free therapies and alternatively preserved therapies. Various advantages of preservative-free therapies for ocular health have been demonstrated ${ }^{(17,18,20)}$. Alternative preservatives (eg, Purite ${ }^{\circledR}$ from Allergan; SofZia ${ }^{\circledR}$ buffer system and Polyquad ${ }^{\circledR}$ preservative from Alcon) are intended to be gentler to the ocular surface than BAK ${ }^{(21)}$ and have been used in reformulating BAK-preserved IOP-lowering medications, which may offer patients with glaucoma or ocular hypertension alternate therapies and may reduce their exposure to BAK. Preservative-free 
A
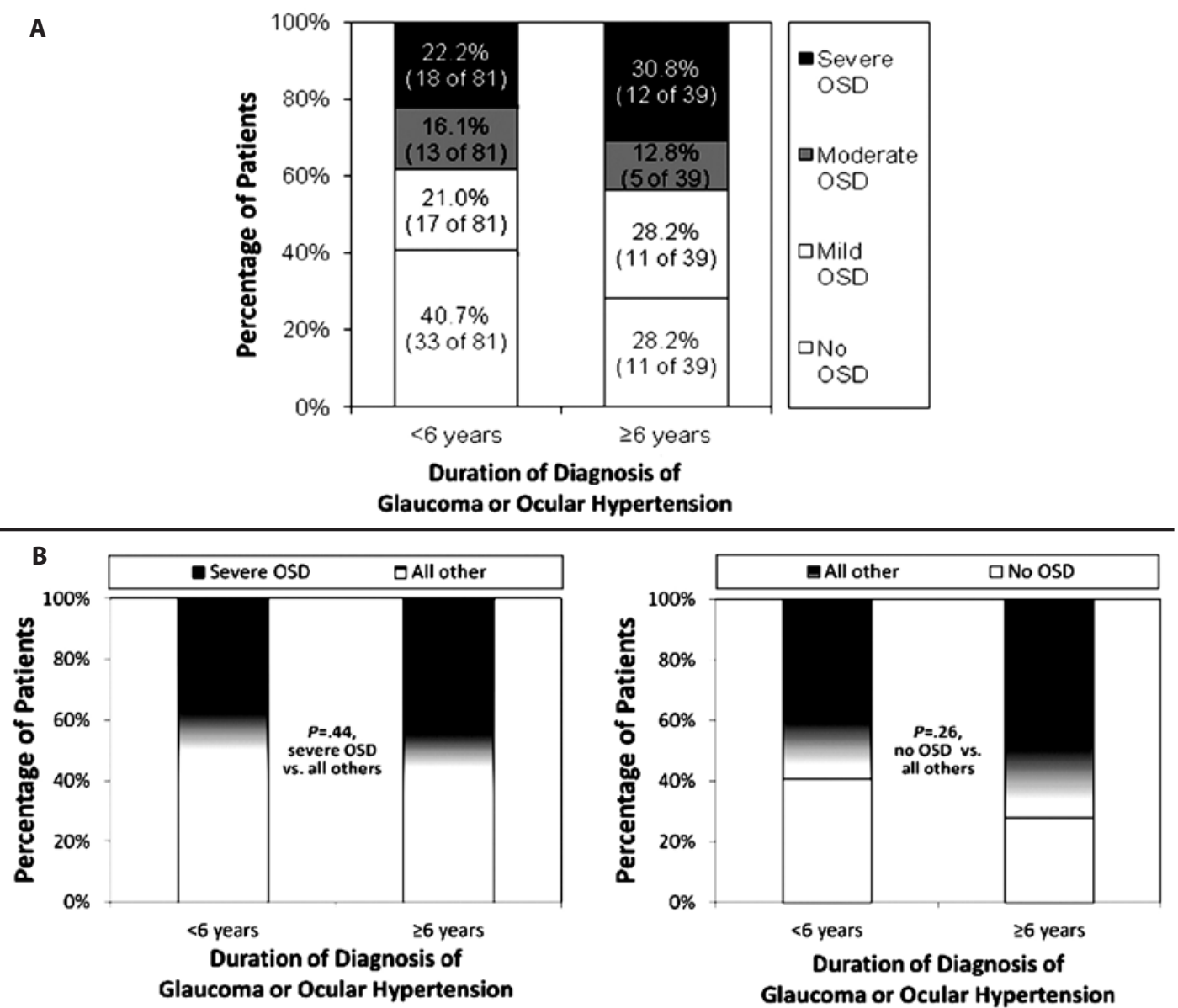

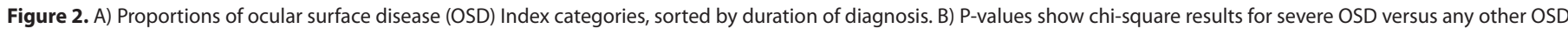
category (left panel) or no OSD versus any other OSD category (right panel).

or alternatively preserved therapies may be important to potentially help preserve the ocular surface health of patients who use ophthalmic product(s) over many years.

Some studies have reported associations between worse OSD or dry eye and longer-term use of IOP-lowering medications (in terms of a surrogate for that variable - longer duration of diagnosis). These associations have been observed as trends over time ${ }^{(13)}$ and as significant differences between duration categories ${ }^{(10)}$. In the current study, patients who had glaucoma or ocular hypertension for $<6$ years had mean OSDI scores of $22 \pm 20$, indicative of mild OSD, while patients with longer histories of glaucoma or ocular hypertension had worse mean OSDI scores $(25 \pm 20)$, indicating moderate OSD; however, the difference in scores was not statistically significant.

Some study limitations were related to the multitude of variables. This was evident in the wide variation (ie, large SDs) in the mean OSDI scores for the population, which made data interpretation complicated. The pathogenesis of OSD in patients with glaucoma is multifactorial. While the role of preserved topical ocular drops in OSD has been well-studied, other anterior segment ocular conditions (eg, blepharitis, allergies, or anatomic abnormalities of the eyelid[s]) are known to exacerbate OSD(2). Collecting data about comorbid conditions and determining the impact of all these factors on the OSD prevalence was beyond the scope of this study.

An additional study limitation was the nature of the OSDI translation. While a recent translation to Portuguese of the OSDI has been reported to have good inter-observer and intra-observer agree- ment(22), that version was not available to us at the time of our study. Supplementing the subjective OSDI with objective assessments of the ocular surface would have made it possible to determine the prevalence of OSD rather than simply presenting the prevalence of its symptoms. However, the purpose of the study was solely to examine the prevalence of ocular surface complaints in Brazilian patients on IOP-lowering therapy, and this aim was accomplished. Although it would have been interesting to determine the prevalence of OSD, the correlation between the signs and symptoms of OSD has been poor ${ }^{(23)}$.

Despite study limitations, findings for these patients in Brazil were generally in agreement with studies in other countries that observed a high prevalence of ocular surface complaints among patients with glaucoma or ocular hypertension. A recent report examining factors related to glaucoma treatment compliance among Brazilian patients revealed that side effects of eye drops were the most frequently cited reason for noncompliance ${ }^{(24)}$. This suggests that patients scoring high on the OSDI, half of whose 12 items deal directly with ocular discomfort, may be at risk for noncompliance.

\section{CONCLUSION}

Thus, Brazilian clinicians should be aware of the high prevalence of abnormal OSDI scores among patients with glaucoma or ocular hypertension and should address any ocular surface complaints in these patients so that they can maintain compliance with their IOPlowering medications. 


\section{ACKNOWLEDGEMENTS}

Alcon Research, Ltd. sponsored this study and provided the services of medical writers and editors for assistance with preparing this manuscript.

\section{REFERENCES}

1. Leung EW, Medeiros FA, Weinreb RN. Prevalence of ocular surface disease in glaucoma patients. J Glaucoma. 2008;17(5):350-5

2. Stewart WC, Stewart JA, Nelson LA. Ocular surface disease in patients with ocular hypertension and glaucoma. Curr Eye Res. 2011;36(5):391-8.

3. Skalicky SE, Goldberg I, McCluskey P. Ocular surface disease and quality of life in patients with glaucoma. Am J Ophthalmol. 2012;153(1):1-9.e2. Comment in Am J Ophthalmol. 2012;153(5):1003; author reply 1003-4.

4. Goto E, Yagi Y, Matsumoto Y, Tsubota K. Impaired functional visual acuity of dry eye patients. Am J Ophthalmol. 2002:133(2):181-6.

5. Schein OD, Muñoz B, Tielsch JM, Bandeen-Roche K, West S. Prevalence of dry eye among the elderly. Am J Ophthalmol. 1997;124(6):723-8.

6. Schmier JK, Covert DW. Characteristics of respondents with glaucoma and dry eye in a national panel survey. Clin Ophthalmol. 2009;3:645-50.

7. Ghosh S, O'Hare F, Lamoureux E, Vajpayee RB, Crowston JG. Prevalence of signs and symptoms of ocular surface disease in individuals treated and not treated with glaucoma medication. Clin Experiment Ophthalmol. 2012;40(7):675-81.

8. Baffa Ldo P, Ricardo JR, Dias AC, Módulo CM, Braz AM, Paula JS, et al. Tear film and ocular surface alterations in chronic users of antiglaucoma medications. Arq Bras Oftalmol. 2008;71(1):18-21.

9. Baudouin C, Labbé A, Liang H, Pauly A, Brignole-Baudouin F. Preservatives in eyedrops: the good, the bad and the ugly. Prog Retin Eye Res. 2010;29(4):312-34.

10. Garcia-Feijoo J, Sampaolesi JR. A multicenter evaluation of ocular surface disease prevalence in patients with glaucoma. Clin Ophthalmol. 2012;6:441-6.

11. Rossi GC, Tinelli C, Pasinetti GM, Milano G, Bianchi PE. Dry eye syndrome-related quality of life in glaucoma patients. Eur J Ophthalmol. 2009:19(4):572-9.

12. Miller KL, Walt JG, Mink DR, Satram-Hoang S, Wilson SE, Perry HD, et al. Minimal cli- nically important difference for the ocular surface disease index. Arch Ophthalmol. 2010;128(1):94-101.

13. Erb C, Gast U, Schremmer D. German register for glaucoma patients with dry eye. I. Basic outcome with respect to dry eye. Graefes Arch Clin Exp Ophthalmol. 2008;246(11): 1593-601.

14. Fechtner RD, Godfrey DG, Budenz D, Stewart JA, Stewart WC, Jasek MC. Prevalence of ocular surface complaints in patients with glaucoma using topical intraocular pressure-lowering medications. Cornea. 2010;29(6):618-21.

15. Novaes P, Saldiva PH, Matsuda M, Macchione M, Rangel MP, Kara-José N, et al. The effects of chronic exposure to traffic derived air pollution on the ocular surface. Environ Res. 2010;110(4):372-4

16. Pflugfelder SC, Baudouin C. Challenges in the clinical measurement of ocular surface disease in glaucoma patients. Clin Ophthalmol. 2011;5:1575-83.

17. Ciancaglini M, Carpineto $P$, Agnifili L, Nubile M, Fasanella V, Lanzini M, et al. An in vivo confocal microscopy and impression cytology analysis of preserved and unpreserved levobunolol-induced conjunctival changes. Eur J Ophthalmol. 2008;18(3):400-7.

18. Martone G, Frezzotti P, Tosi GM, Traversi C, Mittica V, Malandrini A, et al. An in vivo confocal microscopy analysis of effects of topical antiglaucoma therapy with preservative on corneal innervation and morphology. Am J Ophthalmol. 2009;147(4):725-35.e1.

19. Katz G, Springs CL, Craven ER, Montecchi-Palmer M. Ocular surface disease in patients with glaucoma or ocular hypertension treated with either BAK-preserved latanoprost or BAK-free travoprost. Clin Ophthalmol. 2010;4:1253-61.

20. Pisella PJ, Pouliquen P, Baudouin C. Prevalence of ocular symptoms and signs with preserved and preservative free glaucoma medication. Br J Ophthalmol. 2002;86(4):418-23.

21. Yee RW. The effect of drop vehicle on the efficacy and side effects of topical glaucoma therapy: a review. Curr Opin Ophthalmol. 2007;18(2):134-9.

22. Prigol AM, Tenório MB, Matschinske R, Gehlen ML, Skare T. Tradução e validação do índice da doença da superfície ocular para a língua portuguesa. Arq Bras Oftalmol. 2012;75(1):24-8.

23. Nichols KK, Nichols JJ, Mitchell GL. The lack of association between signs and symptoms in patients with dry eye disease. Cornea. 2004;23(8):762-70.

24. Silva LR, Paula JS, Rocha EM, Rodrigues ML. Fatores relacionados à fidelidade ao tratamento do glaucoma: opiniões de pacientes de um hospital universitário. Arq Bras Oftalmol. 2010;73(2):116-9. 